\title{
Services Available in the Transfusion Medicine Department of Sir Salimullah Medical College and Mitford Hospital
}

\author{
Kazi Mariam Naher ${ }^{1, ~ *, ~ S h a f i a ~ S h a h e e n ~}{ }^{2}$, Baizid Khoorshid Riaz ${ }^{1}$ \\ ${ }^{1}$ Department of Public Health and Hospital Administration, National Institute of Preventive and Social Medicine (NIPSOM), Mohakhali, \\ Dhaka, Bangladesh \\ ${ }^{2}$ Department of Epidemiology, National Institute of Preventive and Social Medicine (NIPSOM), Mohakhali, Dhaka, Bangladesh
}

Email address:

dr.kazimariam@gmail.com (K. M. Naher)

*Corresponding author

To cite this article:

Kazi Mariam Naher, Shafia Shaheen, Baizid Khoorshid Riaz. Services Available in the Transfusion Medicine Department of Sir Salimullah Medical College and Mitford Hospital. International Journal of Cardiovascular and Thoracic Surgery. Vol. 7, No. 1, 2021 , pp. 1-7. doi: $10.11648 /$ j.ijcts.20210701.11

Received: December 15, 2020; Accepted: December 24, 2020; Published: March 10, 2020

\begin{abstract}
Background: Blood, is a scarce non substitute, which necessitates it for patients to have a reliable safe access to blood products at all levels. In order to identify the shortcomings in this process, this study has been designed to assess the current status of the transfusion medicine department services in one of the tertiary level hospital in Dhaka city. Subjects and Method: This cross-sectional study was conducted in the Transfusion Medicine department of Sir Salimullah Medical College and Mitford Hospital, Dhaka in 2018. The study population was a total of 275 (14 Service Providers purposively interviewed \&261 blood donors taken as per convenience). Data was collected by using semi structured questionnaire, open- ended questionnaire from the Head of the Department and check list. Results: The findings revealed that all basic tests and mandatory screening tests were conducted in the unit except Bone Marrow examination and Apheresis. Important record registers (Donor care, Donor deferral register etc.) were present but not updated. Few SOPs were available but were not kept at work stations. No screening curtains were provided for donor privacy and no technicians used gloves at work. Only $1.5 \%$ donors were Voluntary. About 36\% were first time donors. About 19\% of donors mentioned a delay of nearly an hour for completion of donation process, though $80.5 \%$ donors were still satisfied with staff behavior. WHO criteria was followed for Donor selection in the unit. Pre and post donation counselling was extremely dissatisfying. Despite of no stocks, the unit organized mere Voluntary Blood donation activities. Conclusion: A huge number of patients rely on tertiary hospitals for blood transfusions, as it is a life-saving procedure. Voluntary blood donation can be increased by encouraging Government-NGO collaboration along with use of software for holding details of regular donors.
\end{abstract}

Keywords: Blood Transfusion, Services, Tertiary Hospital, Dhaka

\section{Background}

A robust, sustainable blood system is a crucial component of a healthcare system [7]. Blood transfusion refers to the therapeutic infusion of blood, blood components and blood products, a process involving donor recruitment, selection and collection, donor testing, handling/administering blood, risk of infectious disease transmission, product manufacture, and therapeutic apheresis. An effective Blood Transfusion Service is an integral component in the provision of an adequate health care service that aims to ensure the safety, adequacy, accessibility and efficiency of blood supply at all levels (WHO) [6]. The national blood system should be governed by national blood policy and legislative framework to promote uniform implementation of standards and consistency in the quality and safety of blood and blood products [17]. Implementation of Safe Blood transfusion started in 1997 in Bangladesh. The National Safe Blood Transfusion Program, supported by World Health Organization (WHO), under Ministry of Health and Welfare developed and the formulated the National Blood Policy and the National Strategy for Voluntary Blood Donation [14]. Safe blood Transfusion Programme, 2009 was sponsored by 
United Nations Development Programme (UNDP) in 20002004 and from 2004-onwards is supporting by WORLD BANK, Development for International Development (DFID), World Health Organization (WHO) and Health, Nutrition and Population Sector Programme (HNPSP). World Health Organization (WHO), Country Office for Bangladesh, has supported the National Safe Blood Transfusion Program, under Ministry of Health and Welfare to develop blood donor recruitment guidelines and the formulation of the National Blood Policy. Furthermore, WHO provided technical assistance in the development of the National Strategy for Voluntary Blood Donation an important component for an increased blood donation [19]. In Bangladesh there is no centralized blood collection system at national level and no organization has been delineated to support voluntary blood donation in the country. A few philanthropic organizations (Sandhani, Medicine Club, Bangladesh red crescent society, Quantum, SpandanB) promote voluntary blood donation [9, 18]. Globally, about 118.5 million blood donations are collected annually. An increase of 7.8 million blood donations from voluntary unpaid donors from 2013 to 2018 has been reported by 156 countries. An increase in absolute numbers of 2.37 million was reported in South-East Asia [2]. Compiled reports from blood centers under public and private sectors in Bangladesh, revealed that over 600,000 units of blood were collected in 2016 against an estimated demand of 800,000 . From an assessment conducted by WHO in 20 districts hospitals of Bangladesh, it was found that only half of the public blood centers were engaged in blood donor recruitment. Only half of the district health facilities kept blood stocks but $41.4 \%$ faced shortage of supply in the reporting period, indicating a general gap between blood demand and supply [13]. Blood is a scarce and a costly resource with no substitute. Blood usage is highest in Medical College Hospitals using approximately $56 \%$ of total blood collections. [9] Patients requiring transfusion should have reliable access to safe blood products without delay. This study aims to assess the current status of the services provided in a transfusion medicine department which will help to identify the gaps in the department thereby helping to create a foundation for long-term planning, implementation and sustainable result.

\section{Subjects and Methods}

\subsection{Study Design}

A cross-sectional study was conducted in the Transfusion Medicine department of Sir Salimullah Medical College and Mitford Hospital in Dhaka 2018.

\subsection{Population and Sample}

The study population were 14 Service Providers (Doctors, Medical Technologists, MLSS, Clerks and Cleaners) purposively interviewed and 261 blood donors, taken as per convenience, with a sample size of 275 . The method of approach for data collection was mixed. Qualitative data was collected via observational checklists.

\subsection{Study Variables}

Data were collected on the services available and the activities performed prior/after in the department in regard to blood donation which were the dependent variables. Key Informant Interview included the independent variables with information regarding Apheresis, the screening test status per month, screening methods used, Standard Operating Procedures (SOPs) in the department, donor cards, blood products temperature regulation details, donor criteria followed in the department, and voluntary donation promotions. Observational checklist was made to assess the Screening tests, Immunological tests, Donor selection, Safety precautions, donor Evaluations and Documentation maintenance. Routine and special tests availability, protocols for proper service delivery activities and document\& record maintenance were identified to assess the services of the department and were the independent variables.

\subsection{Operational Definitions of Variables}

Blood - Blood is a body fluid in humans and other animals that delivers necessary substances such as nutrients and oxygen to the cells and transports metabolic waste products away from those same cells.

Blood Transfusion

A blood transfusion is the transfer of blood or blood products from one person (donor) into another person's bloodstream (recipient), usually done as a lifesaving maneuver to replace lost blood components.

Apheresis

Procedure whereby whole blood is separated by physical means into components and one or more of them is returned to the donor.

Standard Operating Procedure

An SOP is a written document of instruction to perform various operations in a testing site which provides step-bystep instructions to ensure consistency, accuracy, quality of a laboratory process.

Donor

A person who gives whole blood or one of its components for transfusion.

Blood component

Any therapeutic constituent of blood that is separated by physical or mechanical means (e.g. red cells, platelets, plasma).

Donor selection

The process of assessing the suitability of an individual to donate blood or blood components against defined selection criteria

Voluntary Donor

A person who donates blood (and plasma or cellular components) of his/her own free will and receives no payment for it, either in the form of cash, or in kind which could be considered a substitute for money. 


\section{Donor deferral}

The non-acceptance of a potential blood donor to donate blood or blood components, either temporarily or permanently, based on general health or medical condition, or the risk of exposure to pathogens

Blood transfusion service (BTS)

A generic term to describe an organization (s) that is involved in the provision of blood for transfusion; its activities may be carried out by a single blood centre or through a network of blood centres and hospital blood banks

Blood collection

A procedure whereby a single donation of blood is collected in an anticoagulant solution.

\subsection{Study Instruments}

Qualitative data was collected via observational checklists. Face to face interview by semi-structured questionnaire and Key Informant Interview (Head of the Department) by an open-ended questionnaire was conducted among the respondents. Pre-tested semi-structured questionnaire was drafted and translated to Bengali.

\subsection{Data Analysis}

Data were entered, cleaned and re-coded using Statistical Package for Social Sciences (SPSS) version 23 and the descriptive analysis were represented in tables, graphs and pie charts.

\subsection{Research Ethics}

Ethical permission for the study was taken from Ethical Review Committee of National Institute of Preventive and Social Medicine (NIPSOM) on May 08, 2018. All ethical issues related to the research involving human subject was addressed according to the guidelines imposed by BMRC (Bangladesh Medical Research council) \& the ethical review committee of the WHO. A consent form was supplied \& written consent obtained before the actual interview. Related forms \& questionnaire were attached. Permission from the hospital authority was taken.

\section{Results}

\subsection{Sample Characteristics}

The respondents were the service providers and service receivers. Service Providers: The department had 18 assigned posts as per the departmental organogram. The posts for Biochemist, Chief Technician and one cleaner were vacant. The department did not have Lab assistants. (Table 1). Service Receivers: These were the donors who came in to donate blood and who were willing to participate in the process. About $56.7 \%$ of the Service receivers were between 18 to 27 years, $37.5 \%$ of them were between $28-37$ years, $5 \%$ of them were between $38-47$ years, $0.4 \%$ were between 48 to 57 years and $0.4 \%$ only above 57 years. The mean age of the respondents were found to be 27.38 years, median was 26 , mode 24, SD ( \pm 6.168$)$, minimum age was 18 years and maximum was 60 years. (Table 2)

Table 1. Manpower scenario of the Department.

\begin{tabular}{llll}
\hline Designations & $\begin{array}{l}\text { Post } \\
\text { Available }\end{array}$ & $\begin{array}{l}\text { Current } \\
\text { staffs }\end{array}$ & Post vacant \\
\hline Professor & 1 & 1 & \\
Associate Professor & 1 & 1 & \\
Assistant Professor & NA & 0 & \\
Medical Officer & 3 & 3 & - \\
Emergency MO & 2 & 2 & 1 \\
Biochemist & 1 & 0 & 1 \\
Chief Technician & 1 & 0 & - \\
Medical Technologist & 3 & 3 & - \\
Lab Assistant & NA & 0 & - \\
Clerk & 1 & 1 & - \\
MLSS & 3 & 4 & 1 \\
Cleaner & 2 & 1 & \\
Transfusion Committee & 9 members & & \\
\hline
\end{tabular}

Table 2. Distribution of Respondents according to Age $(n=261)$.

\begin{tabular}{lll}
\hline Age group (in years) & Frequency & Percentage (\%) \\
\hline $18-27$ & 148 & 56.7 \\
$28-37$ & 98 & 37.5 \\
$38-47$ & 13 & 5.0 \\
$48-57$ & 1 & .4 \\
$>58$ & 1 & .4 \\
TOTAL & 261 & 100 \\
\hline
\end{tabular}

\subsection{Services in the Department}

\subsubsection{Available Tests}

The department conducted all the routine tests, cross matching and screening tests related with blood transfusion except Hemolysin tests, Red cell reagent preparation, Autoantibody, Bone Marrow examinations and Apheresis. They prepared all blood components except Cryoprecipitate. All screening tests were conducted in the unit except HIV NAT, HCV NAT, Human T-cell lymphotrophic virus - anti HTLV I and II.

\subsubsection{Document and Records}

Process flowcharts, Instrument operation manuals, copies of SOPs, Donor care register, Donor deferral register and waste management registers were present yet not maintained. Except the SOP for blood grouping, cross matching and screening, no other SOPs were available.

\subsubsection{Blood Stocks}

The department kept no blood stocks. Blood collected are manually upgraded on a daily basis. Unused Blood are discarded after storing for maximum of 32-35 days.

\subsubsection{Regarding Quality Control of Blood Components}

No Quality Control program is present in the department to monitor the quality of blood components.

\subsubsection{Performance of Routine Activities Associated with Proper Service Delivery}

Inventory maintenance and monitoring of the validation of kits, reagents and blood bags were properly done. About $(91.7 \%)$ of staffs admitted to supply the blood within one 
hour of donor waiting time, though about $(19 \%)$ of donors mentioned that it took nearly an hour or more from screening to completion of donation process. Cross checking of blood bag with patient details before handover was conducted by $(91.7 \%)$ of staffs.

\subsubsection{Satisfaction of the Respondents Regarding the Behavior of the Staffs}

Nearly $(20.7 \%)$ of the donors had to wait for more than an hour for blood testing and donation process. Almost (80.5\%) donors were satisfied with the staff behavior. (Figure 1)

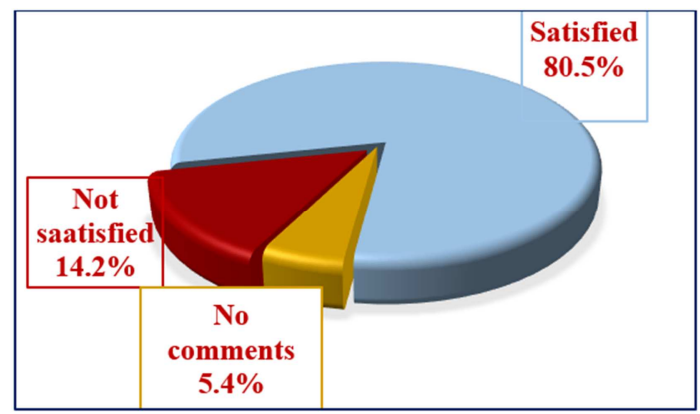

Figure 1. Pie diagram showing the Opinions of the respondents on the behavior of the staffs $(n=261)$.

\subsection{Blood Donation Activities in the Transfusion Medicine Department}

\subsubsection{Donor Recruitment Activities in the Department}

No activities was conducted for recruitment of voluntary donors. Table 2 shows the Donor criteria being followed by the department.

Table 3. Donor Criteria followed in the department.

\begin{tabular}{ll}
\hline Vitals & Criteria \\
\hline Age range & $18-60$ years \\
$\begin{array}{l}\text { Minimum Hemoglobin level } \\
\text { (Male and Female) }\end{array}$ & $11 \mathrm{~g} / \mathrm{dl}$ \\
Minimum weight & $50 \mathrm{~kg}$ \\
Pulse Rate & $80-120$ beats $/ \mathrm{min}$ \\
Blood pressure & Systolic: $100-130 \mathrm{~mm} / \mathrm{Hg}$ Diastolic: \\
& $60-90 \mathrm{~mm} / \mathrm{Hg}$ \\
\hline
\end{tabular}

\subsubsection{Pre and Post Donation Activities in the Department}

No screening curtains were provided for donor privacy. None of the technicians used gloves while donation. Only $(41 \%)$ of donors were told about the venipuncture process and $(22.6 \%)$ were informed the duration of the process before donation. None of the Donors were counseled on the post donation complications and their management (according to standard guidelines) prior to donation. About (74.3\%) of them did not receive any post donation advice. None of the donors received any motivation from the staffs regarding Voluntary Blood donation. There was no arrangement for any refreshment except water for the donors post donation.

\subsubsection{Purpose of Donation of the Respondents}

From Figure 2, it is seen that $(70.1 \%)$ came to donate blood to their relatives, $(28.4 \%)$ of the donors came to help a friend and only (1.5\%) were Voluntary donors. About (63.6\%) and
(36.4\%) of them were old and new donors respectively.

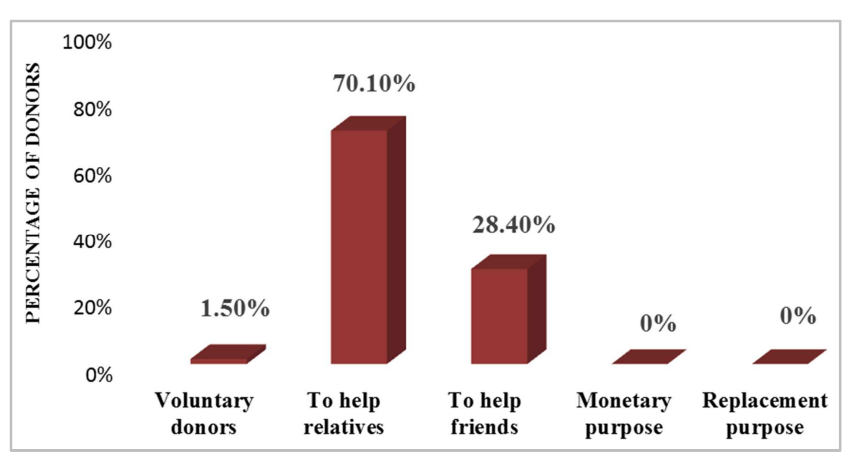

Figure 2. Bar diagram showing the donors types visiting the unit $(n=261)$.

\subsection{Key Informant Information}

The unit started its activities in 1948. On an average, the department attends at least 50 donors a day. Approximately 1300 units of blood was supplied from the department in September 2018. In the same month, 1,317 screening tests were conducted out of which $7 \mathrm{HBV}$ and 1 VDRL positive were found. Rapid testing method was used for screening. ELISA was not done in the department. Platelet Apheresis was held from May 2012 till May 2018 within which 17 patients took the service. Due to the extremely expensive disposable set $(14,800 \mathrm{tk})$ and the unaffordability of the local donors, Apheresis is currently off. Data entry is done manually. Maximum Blood Ordering Schedule is not maintained. Voluntary Blood donation camps were arranged only on the National Mourning Days each year. A total of 13 units of blood were collected in the last camp (August $15^{\text {th }}$ 2018). Most of the voluntary donors were the medical students residing in the campus.

\section{Discussion}

\subsection{Services in the Transfusion Medicine Department}

\subsubsection{Screening \& Serological Tests and Special Tests}

From the study, the unit conducted the screening tests for the mandatory diseases according to Safe Blood Transfusion Program, except screening tests for HIV AT, HCV NAT and Human T-cell lymphotrophic virus - anti HTLV I and II and bone marrow examinations. Rapid testing method was used for screening. Since ELISA was not done in the department, slides were sent to the Microbiology departments when needed, in which case the tests were done free of cost. According to a study in 2011, a total of 2,03,304 units of blood components were produced by the blood centers [20]. This was in contrast to the study. Apheresis was unavailable in the department. Besides, patients who could afford it would prefer to perform it in Dhaka Medical College and Hospital. Screening of all donated blood for markers of five TTI (HIV, HBV, HCV, syphilis and malaria) is mandatory in Bangladesh and $100 \%$ donations are screened in all centres except for $20 \%$ of district hospitals, $55 \%$ of Upazila health complexes. In $98 \%$ of the centres, blood screening was 
carried out using rapid tests [9]. Out of 109 centres surveyed in a study, only one public institute had record of blood collection for platelet components collected by apheresis [5].

\subsubsection{Screening Test Scenario in a Month of the Study Period}

From the data of the Key informant, in a month, it was found that 1,317 screening tests were conducted in total, out of which $7 \mathrm{HBV}$ positive and 1 VDRL positive were found. On observation, the patient details of deferred cases were not noted. From a study held in Sir Salimullah Medical College and Hospital in 2010, the prevalence of HBV, HCV, HIV and Syphilis were found to be $2.19,0.25,0.06$ and $0.15 \%$ respectively [1].

\subsubsection{Donor Handling}

The checklist for Transfusion in a hospital must include a number of protocols- from proper collection, accurate blood samples labelling, correct blood units handling, safe blood administration, patient monitoring before, during and after transfusion to adverse transfusion events management [12]. Contrarily, in the current study, it was noticed that $16.9 \%$ of the donors were not examined properly by the physicians, missing out either their weight measurement or BP. No screening curtain was available for privacy of the donors. Less than $8 \%$ of the staffs admitted to skip cross checking of the blood bag label with patient details. No health personnel used gloves while performing any activities, thereby hindering the protocol.

\subsubsection{Records and Document Maintenance}

Every Blood bank must have SOPs on Donor Issues, Component Separation, Immuno-haematology, Screening of transfusion transmissible infections, Labelling, preservation and storage of blood and components and Quality Assurance [11]. Obsolete versions of SOPs of all procedures written by the performing technologist and verified by supervisor of the area, Quality Assurance Manager and authorized by medical officer in- charge must be archived [8]. From the WHO assessment in private and public blood centres in Nepal, there were no national guidelines developed for Maximum Blood Ordering Schedules (MSBOS) in any centre [13]. This study showed that Process flowcharts, Instrument operation manuals, Donor care, Donor deferral and waste management registers were not maintained in the department. Records were manually maintained. Standard Operating Procedure for Blood Transfusion were not available at respective work stations. SOPs for blood grouping and collection, donor selection, Rh D typing, cross matching and screening tests were available but not kept at workstation. In a similar study conducted among the public and private hospitals in Bangladesh, SOPs were found and reported to be implemented only in one private hospital and one private medical college. No centre kept records of the whole range of documents as required. The donor blood grouping registers were available but incomplete in most of the public hospitals [13]. Compared to another study in Nepal, records in the donor database were maintained by $87 \%$ of the centres and manual entry was most frequently practiced [5].

\subsection{Blood Donation Activities in the Transfusion Medicine Department}

\subsubsection{Donor Types and Criteria}

More than three-fourth of the donors came to donate for relatives and less than 2 percent were Voluntary donors which indicated a rare Voluntary blood donation in the department. On the other hand, SANDHANI unit, a voluntary institution governed by Medical and Dental students of SSMC, was banned by academic council. From the data in a study, $85 \%$ of blood were collected from relatives/family and only $15 \%$ of blood were donated by voluntary non-remunerated blood donors in all centres [13]. None of the donors received any motivational words from the staffs regarding Voluntary Blood donation. According to a study by WHO, the selection of blood donors should be based on regularly reviewed selection criteria, without discrimination of any kind including gender, race, nationality or religion [15]. The BTS has a duty of care to provide counselling to all deferred donors and referral for their further management. This did not apply in the study as counselling was poorly practiced here in the department. In Bangladesh, donors are selected according to the following important eligibility criteria: Donor Age: between 18 to 60 years, Haemoglobin: not $<12.5 \mathrm{~g} / \mathrm{dL}$ for males and $11.5 \mathrm{~g} / \mathrm{dL}$ for females, minimum $45 \mathrm{~kg}$ weight, Blood pressure: systolic: $100-140 \mathrm{~mm} \mathrm{Hg}$ and diastolic: $60-90 \mathrm{~mm} \mathrm{Hg}$ is recommended without anti-hypertensive, Oral temperature shall not exceed $37.5^{\circ} \mathrm{C}$, Pulse: 60 to 100 regular beats per minute, Donation interval: 3 to 4 months [4]. This was in accordance to the study conducted.

Among Service Receivers, more than half the donors belonged to the age group 18-27 years. This was different from other studies where the global findings as per a study by WHO in 2017 , were $40 \%$ between $25-44$ years, and where 45-64 years and 18-24 years contributed $29 \%$ and $23 \%$ of the total donations, respectively [17]. In the study at $\mathrm{DMCH}$, the highest number of donors were between 41-80 years which was about $83.82 \%$ [21].

\subsubsection{Donor Deferral}

An estimated 1.6 million units are discarded due to the presence of infectious markers for TTI, including HIV, hepatitis $\mathrm{B}$, hepatitis $\mathrm{C}$ and syphilis in Bangladesh. At least 13 million prospective donors are deferred [3]. In this study, deferred patients were not properly recorded in the department.

\subsubsection{Counseling}

In contrary to the Stages of Blood donor counselling in WHO guidelines, none of the staffs counseled on the complications following the donation [10]. Only two-fifth of the donors were briefed on the venipuncture process. More than three-fourth of the donors did not receive any post donation advice. As per a study in Bangladesh, only $36 \%$ of public medical colleges, reported to hold pre donation 
counseling and interviews routinely before blood donation [15].

\subsubsection{Voluntary Blood Donation Camps}

World Blood Donation day June $14^{\text {th }}$ was poorly observed in the department. Voluntary blood donation camps were only held on National Mourning Days. In another survey conducted by WHO, except 2 NGOs, no centres observed World Blood Donor Day [15]. In another article, it was suggested that voluntary blood donation could be encouraged on celebrating days like International Cancer Day (4th February), International Haemophilia Day (17th April), International Thalassemia Day (8th May) and World Voluntary blood donors Day (17th June) which can motivate and educate our society in Bangladesh [16].

\section{Limitations of the Study}

Due to the inadequate manpower, the study had to include staffs like MLSS, with limited experience and skill. Their knowledge wasn't helpful to fill in with information regarding the services of the department. Since the practice of documentation and recording was not up to the standard, there was some degree of variability in response rates to few specific questions (Example: deferral register, waste register) making analysis difficult.

\section{Conclusion}

As per the findings, technicians did not use gloves while handling the donors. SOPs for Blood Transfusion were not maintained. Data maintenance was still done manually. Due to lack of motivational programs Voluntary donation was negligible in the department. There were positive screening tests during the study period which were not recorded. The study revealed that there was very weak pre and post counselling of donors which did not fulfill WHO guidelines. More than three-fourth of the donors did not receive any post donation advice. Voluntary blood donation camps were only held only on selective days. The findings of this study can be used to bring improvement in the management of the department.

\section{Recommendations}

Periodic revision of SOPs and guidelines should be done and made available at the work station. Standardized documentation and a data management system should be developed for systematic record keeping. Registers for blood donation, blood deferrals and laboratory procedures must be uniformly maintained. Electronic database must be introduced. Voluntary donations must be encouraged along with promotion by campaigning by GOVT-NGO collaboration. Since there is negligible voluntary donation in the unit, with no blood stocks, there must be a register/software for holding details of regular donors, who can be communicated with in case of lack of needed blood.
Pre and post-donation counselling must be made a core activity, with trained personnel. Efforts can be made in order to re start the Platelet Apheresis service.

\section{Financial Support and Sponsorship}

This study is self-funded.

\section{Conflict of Interest}

There are no conflicts of interest in this study.

\section{Acknowledgements}

The author would like to express sincere gratefulness to Prof. Dr. Baizid Khoorshid Riaz and Dr. Shafia Shaheen, who were the co-authors as well, who have helped in framing the research outline; the authority of Sir Salimullah Medical College and Mitford Hospital for allowing this study to be carried out.

\section{References}

[1] Article, O. (2010) 'Prevalence of Transfusion Transmitted Infection in Healthy Blood Donors in Sir Salimullah Medical College', pp. 68-70.

[2] www.who.int. (n.d.). Blood safety and availability. [online] Available at: http://www.who.int/en/news-room/factsheets/detail/blood-safety-and-availability [Accessed 19 Sep. 2020].

[3] Donation, B. (no date) 'Donor Selection Donor Selection'.

[4] Interns, M. (no date) 'WHO Clinical Transfusion Guidelines.'

[5] GoN (2011) 'Mapping and Comprehensive Assessment of Blood Transfusion Services in Nepal'.

[6] Mohammad, N. A. sadat et al. (2010) 'Safe Blood Transfusion and Ethical Issues in Transfusion Medicine', Journal of Dhaka Medical College, 19 (2), pp. 144-149.

[7] Mulcahy, A. W. et al. (no date) Toward a Sustainable Blood Supply in the United States An Analysis of the Current System and Alternatives for the Future.

[8] National AIDS Control Organisation (2007) 'Standards for Blood Banks \& Blood Transfusion Services', Ministry of Health and Family Welfare, pp. 1-101. doi: 10.1017/CBO9781107415324.004.

[9] Plan, N. S. (2013) 'Voluntary Non - Remunerated Blood Donation in Bangladesh'.

[10] Program, B. S. (2011) 'Comprehensive assessment study of Blood Transfusion Service, Bhutan-2011 Comprehensive Assessment Study of'.

[11] QSAEC, Q. S. A. E. C. (2014) 'Standard Operating Procedure for Blood Transfusion', http://education.qld.gov.au/curriculum/area/science/docs/soppoultry.pdf (Accessed: 30/06/2015). 
[12] Transfusion, C. and Safety, P. (2010) 'Hospital requirements for safe clinical transfusion and patient safety Key elements'. Available at: www.who.int/bloodsafety.

[13] WHO Bangladesh and Government of Bangladesh (2012) 'Situation assessment of public and private blood centers in Bangladesh'. Available at: http://apps.who.int/bloodsafety/transfusion_services/Banglade sh_SituationAssessmentPublicPrivateBloodCentres.pdf.

[14] World Blood Donor Day 2018: An Action of Solidarity." Www.Who.Int, 14 June 2018, www.who.int/bangladesh/news/detail/14-06-2018-worldblood-donor-day-2018-an-action-of-solidarity. Accessed 19 Sept. 2020.

[15] World Health Organization, 2012. Blood donor selection: guidelines on assessing donor suitability for blood donation. World Health Organization.

[16] Dipta, T. F. and Rahman, M. T., (2009). Safe blood transfusion: past, present and future. Bangladesh Journal of Pathology, 24 (1), pp. 1-2.
[17] World Health Organization (2017) Global Status Report on Blood Safety 2016. Geneva: WHO.

[18] 'Screening Donated Blood for Transfusion Transmissible Infections in Bangladesh National Guidelines 2013 Foreword' (2013).

[19] South-East Asia Regional Office. (n.d.). Bangladesh is still to meet the demand of safe blood supply. [online] Available at: http://www.searo.who.int/bangladesh/blooddonor/en/ [Accessed 3 Dec. 2018].

[20] Dghs.gov.bd. (2012). safe blood transfusion. [online] Available http://dghs.gov.bd/licts_file/images/Health_Bulletin/HB2012 CH/HB2012 CH12 Safe-Blood-Transfusion.pdf [Accessed $\overline{3}$ Dec. 2018].

[21] Karim, S. et al. (2013) 'MANAGEMENT OF VARIOUS PATIENTS IN DAY CARE TRANSFUSION CENTER AT TRANSFUSION MEDICINE DEPARTMENT OF DHAKA MEDICAL COLLEGE HOSPITAL, DHAKA - ANNUAL AUDIT OF 2013', pp. 2013-2015. 